\title{
1. Introduction to Environmental Norms in Maritime Law
}

Environmental norms guide the behaviour of states and societies. Despite their controversial character and their disputed legal effects, environmental norms underpin societal efforts to protect the environment and develop sustainably. States, institutions and existing legal regimes are expected to respond to the increasing concerns of environmental degradation by evolving in ways consistent with environmental norms.

The international and commercial components of maritime law have been in existence long before the environmental norms were developed and their objective has been the facilitation of international trade and the harmonisation of the regulatory arrangements for ships, the major means of international trade. The need to standardise ships and to provide assistance to the plethora of new states after the Second World War led to the establishment of the Inter-governmental Maritime Consultative Organization (IMCO), later renamed as the International Maritime Organization (IMO). This accelerated the harmonisation process through the development of a complex regime of laws and minimum uniform standards. The IMCO, from its inception, aimed at optimising international shipping. The introduction of environmental norms and the development of maritime environmental laws became part of the IMO mandate only after catastrophic shipping incidents focused the attention of the public on a sector which appeared reluctant to increase its costs until faced with the grim consequences of its failures.

The introduction into the 1982 United Nations Convention on the Law of the Sea (LOSC) of a separate chapter on the marine environment created a progressive legal framework for the management of marine pollution. States expressly accepted a legal obligation to protect and preserve the marine environment. ${ }^{1}$

In parallel, marine research accumulated evidence demonstrating the impacts of human activities, including shipping, on the marine but also on the atmospheric environment. Climate change, atmospheric pollution and biodiversity losses put pressure on society to reduce harmful activities. Shipping followed the calls for regulation, always half-heartedly, and with significant

$1 \quad$ LOSC Art. 192. 
delays or after an outcry caused by the environmental impact of casualties. The regulatory changes adopted by the shipping sector have been slow and effected in a way preserving as much as possible the interests of the existing investment in ships. The adopted uniform regulatory approach has transformed shipping into a sector without any commercial incentive for companies to invest in cleaner ships. Instead, technical regulatory solutions have been used to deal with environmental problems without questioning their efficiency or resolving implementation problems. These observations suggest that environmental norms and principles have not been effective in the evolution of the governance of shipping.

This book examines various aspects of public and private maritime law in order to identify the degree of influence environmental norms have had and the barriers which operated as obstacles to their full integration into maritime law. Understanding how environmental norms affect the sectoral regulation of shipping is important in order to address the existing barriers which are evidenced by the reluctance of the shipping sector to discuss, develop and implement efficient environmental standards. An original aspect of the book is the systematic analysis of international legal documents and of documents submitted in the IMO negotiations for the purpose of addressing these issues. The work is presented in the following 10 chapters, each of which has been written as an independent analysis that can be read on its own.

Chapter 2 provides an overview of the multiple impact shipping has on the marine environment on the basis of contemporary scientific knowledge. It also explores the uncertainties accompanying this knowledge which is, for some impacts, quite significant. The synthesis of the existing literature reveals that the some of the impacts of shipping are local and some global. Furthermore there are oceanic areas which are more vulnerable and others which appears quite resilient. Some impacts depend on their timing, and seasonality appear to be important in some cases. The chapters finds that not every impact of a ship's operation is regulated and that assessments of the environmental effects of the whole fleet are not available for many of the impacts.

Chapter 3 provides an outline of the historical development of the international governance of shipping and the role of environmental protection within it. The contemporary shipping governance comprises four components. The first component is that of the international law jurisdictional arrangements with regards to ships. These include the freedom of navigation the high seas and the associated flag state dominance. The establishment of the IMCO, and the subsequent extension of the IMO's mandate to cover environmental issues is the second component. The analysis of the documents establishing the IMO reveals its technical character, which leads to the importance of Classification Societies, the third component, in guiding the rule making. The fourth component concerns the environmental and industrial NGOs which participate in 
the IMO process. An analysis of the documents submitted in the various IMO bodies is presented in this part. This analysis indicates that the discussions in the IMO are dominated by developed states and by NGOs expressing the interests of the shipping industry. The contribution of the environmental NGOs is restricted to the Marine Environment Protection Committee (MEPC), and even there it is not dominant in character.

Chapter 4 discusses the meaning of norms and the distinction between legal and non-legal norms, jus cogens and obligations erga omnes. The character of environmental principles in international law is also discussed and compared with the dominant norm in the international law of the sea, the freedom of navigation.

Chapter 5 presents an original analysis of the usage of terms representing environmental norms in official IMO documents for the period 1999-2019. This is achieved by the examination of the frequency of usage of environmental principles during negotiations and by the contextual analysis of each document and the specific discussion. The analysis concludes that the environmental principles do not seem to have significantly influenced the work of the IMO. Instead the meaning of the norms has been modified in the IMO and they have been dealt with as inferior to the short-term financial interests of the shipping sector. There is no indication that the environmental principles are used in a way that consider the environmental effects of shipping as part of the costs related to the adopted environmental regulation.

In Chapter 6 a complete analysis of all the IMO Conventions is undertaken with a view to identifying the environmental norms that are either expressly supported by the text of the convention or which are supported practically by the way each convention operates. Particular weight is given to MARPOL ${ }^{2}$ as the major legal instrument combating pollution and expressing the preventive principle, and to environmental liability conventions implementing "the polluter pays" principle. The analysis of the conventions which form the preventive part of the regulatory framework, reveals an extensive set of exceptions which protects older ships, ships operating in areas exclusively under the jurisdiction of one state, and ships in particular trades. The grandfathering clauses are particularly problematic because they protect ships that have a relatively higher environmental footprint when compared with newer ships. In addition, they delay the renewal of the fleet and lengthen the life of the older ships because these are cheaper to operate. A second norm apparent in preventive

2 1973/78 International Convention for the Prevention of Pollution from Ships, adopted 2 November 1973, as Modified by the Protocol of 1978 Relating Thereto, adopted 17 February 1978, entry into force, 2 October 1983, 1340 UNTS 62 (MARPOL) 66. 
conventions is the obligation to seek the "highest practicable standards". This is usually implemented by developing regulations which are technically orientated and relatively cheap, for the ships and the shipowner, without evaluating the environmental consequences of the selected solutions. Thus regulations are developed but the benefits they may confer are unknown. The implementation of the adopted standards is, in some of the conventions, suspended if it leads to delays in the operation of the ship. The costs of environmental degradation do not appear to be taken into account in this aspect either.

The "no more favourable treatment" arrangement appears in various IMO Conventions. However the analysis suggests that (a) the way it is written in MARPOL primarily refers to certification requirements; (b) it does not constrain less favourable treatment of ships of non-contracting states; and (c) in every other respect except nationality there are exceptions and exemptions for ships are available to the flag state. Thus it is argued that the "no more favourable treatment" is not a legal norm, except, perhaps, for certification requirements and states can impose standards which are higher than the MARPOL standards on foreign ships. It is also concluded that this sectoral norm is not an obstacle to the operation of the Common But Differentiated Responsibility (CBDR) principle. The analysis of the IMO Conventions also reveals that there is no procedural assessment prior to making the rules nor a formal assessment of the impact of the rules on the environment.

With regard to environmental liability regimes, the analysis supports a number of points. First, it is found that the internalisation of pollution costs is not carried out fully and significant costs are left to be borne by third parties. In particular, environmental remedy and restoration are significantly restricted.

Chapter 7 focuses on the rights of coastal states to intervene in shipping incidents which threaten environmental damage and for enforcing shipping regulations against foreign ships. Pollution incidents have led to an important expansion of the rights of interventions of the coastal state. The development of Part XII of the 1982 LOSC created an advanced, for 1982, framework for enforcement. However, despite the evolution of environmental norms after 1982, the enforcement rights with respect to marine pollution have not evolved further. Instead, the effect of environmental norms appears in relation to "softer" elements of the enforcement jurisdiction in the Exclusive Economic Zone (EEZ), in particular the thresholds in the scope of threat of environmental damage and the links with the interests of the coastal state which permit proceedings to be initiated by the coastal state. The enforcement regime, primarily based on certification by the flag state, provides significant concessions to the shipping industry and constrains the rights of control of port states. The arrangements in place cannot be considered precautionary, nor do they assist in stopping polluting behaviour at sea when such actions are noticed. Instead, they aim to deter future violations via financial penalties. There is no evidence 
that this system works efficiently. The fact that criminal liability for violations of the environmental regulations is a matter for the flag state, save in specific situations, is problematic because the master and the crew members are not, in general, nationals of the flag state and as a result it is suspected that professionals who commit such violations generally avoid prosecution.

Chapter 8 examines the effect environmental norms have on private law aspects of maritime law and contract law in particular. The possibility of illegality for contracts in breach of environmental norms which have been given legal status is discussed first under English law. Second, the relationship between contract law and international conventions is discussed. Some international conventions impose contractual duties affecting environmental performance. Contracts have been used as tools to give effect to international conventions before the latter came into force. Thus a synergy is identified.

The examination of standard contractual forms provides evidence for the use of contract law as an additional enforcer of environmental regulations. Contractual clauses giving legal character to soft obligations are also discussed. The role of corporate social responsibility in promoting environmental norms is considered. The changes in commercial performance brought about by the aforementioned aspects of contract law through their interaction with environmental laws and regulations leads to a discussion on whether the standard of reasonableness in contract and in tort now includes an expectation that maritime contractual performance will always be within the framework set by environmental norms. It is found that the standard of a reasonable person in contractual construction, as well as in the assessment of damages, has expanded so as to include environmental considerations. However, the possibility of implying a term requiring compliance with environmental norms is rejected in view of the requirement of necessity for such terms under English law.

Chapter 9 considers whether environmental claimants are entitled to security through ship arrest and whether they have priority over competing commercial claims. In other words, this chapter examines whether "the polluter pays" principle means that the polluter has to pay the environmental claims first. The right to arrest the ship for civil liability claims is one of the oldest norms in maritime law. The first international convention, the 1952 Arrest Convention, was developed before environmental claims started acquiring importance. As a result, the 1952 Arrest Convention does not provide expressly for environmental claims, but its provisions have to be examined in detail in order to decide whether they can be used in support of such claims. The deficiency of the 1952 Arrest Convention has been addressed by some states through statu- 
tory intervention. By contrast the 1999 Arrest Convention ${ }^{3}$ provides expressly for rights of arrest in respect of all environmental claims. The ranking of environmental claims against tortious, commercial and financial claims express the way environmental rights are valued against pre-existing legal rights.

Chapter 10 considers another important maritime law norm, that of limitation of liability and the way it interacts with rights of recovery and in particular with the polluter pays principle. Limitation of liability, both under global limitation and under the environmental liability conventions, is considered. Restrictions to the polluter pays principle can be found in many aspects of these conventions, including their spatial scope, the substances covered, the type of damages for which compensation is available and, of course, the actual limitation amounts. While the limits of liability for oil pollution damage have only been exceeded in few cases, a fact which suggest that the limitation amounts are adequate, this is only true for the damages covered. The severe restrictions under the current liability regimes in the recovery of costs for remediation and reparation of the environment means that the preservation of the marine environment for future generations has to be funded by the tax payers of the coastal states. This restriction, as well as moral and equity aspects arising from the fact that "the polluter pays" principle is not followed with respect to such damage, appear to be destabilizing the international compensatory system, which is in need of significant improvement.

Chapter 11 synthesises the results of the book. The significant changes in maritime law brought about by the need for environmental protection are discussed, together with the identified barriers to the operation of environmental norms. The effects the sectoral norms have in reducing the efficiency of regulatory efforts and in transferring the financial costs of sustainable development to other sectors are demonstrated. Some of the barriers to sustainable development have legal character while others express operational practices. Changes in the institutional framework accompanied by legal changes should be considered to enable environmental norms to fully operate within maritime law and contribute towards sustainable development. A strategic aim of zero discharges, zero emissions and zero environmental impact is proposed.

3 International Convention Relating to the Arrest of Sea-going Ships (adopted 10 May 1952, entered into force 24 February 1956) 439 UNTS 193 and the International Convention on the Arrest of Ships (adopted 12 March 1999, entered into force 14 September 2011) 2797 UNTS 3. 